\title{
Preface
}

\section{Critical Care Nephrology}

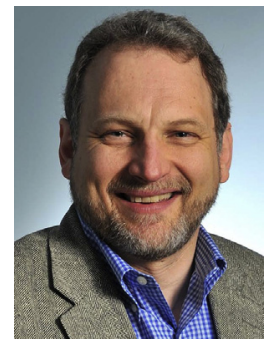

John A. Kellum, MD, FACP

Editor

It's been a decade since Critical Care Clinics first published an issue focusing on Critical Care Nephrology. ${ }^{1}$ I was honored to be the guest editor, and in my preface, I emphasized the changing landscape of critical care medicine in general, and critical care nephrology in particular, arguing that the "age of empiricism" was coming to a close. Indeed, our specialty is decidedly more evidence-based today than it was ten years ago. For critical care nephrology topics such acute kidney injury $(\mathrm{AKI}),{ }^{2}$ renal replacement therapy, ${ }^{3,4}$ and fluid therapy, ${ }^{5,6}$ we now have level 1 evidence where before none existed. Admittedly, we know more about what doesn't work than what does, but this evidence base has dramatically changed the way we approach clinical practice, guideline development, and ultimately, standardization of care. ${ }^{7}$

Yet as I reflect on the past ten years it occurs to me that there are some disturbingly familiar themes. Through much of the decade we sought to treat or prevent AKI by augmenting renal blood flow either with drugs or with fluids. What we continue to demonstrate but never actually learn is that kidney injury isn't "fixed" by giving more fluids or renal vasodilators. Fortunately, there are some new therapies on the horizon and even some simple procedures that might be effective. ${ }^{8}$ However, some of the most important things we can (and should) do are not very "sexy." Early antibiotics and source control for sepsis and avoiding nephrotoxins ${ }^{9}$ would go a long way. Our reluctance to give up long-held beliefs has set us back in part because we have failed to look for alternatives. ${ }^{10}$ Unfortunately, our reluctance to abandon old concepts is also coupled with a desire to embrace things we like. This can lead us to early adoption of treatments we should be more skeptical of (eg, early goaldirected therapy, tight glucose control) and ultimately overturn with large randomized trials. ${ }^{11,12}$

However, not every question we wish to answer should require or is even best answered by mega-trials. If we randomize millions of people to receive one type of chemotherapy or another, we will obscure any effectiveness signal for the very small 
number who have cancer. Even interventions that are given to virtually everyone (eg, fluids) might work differently in different patients. Would we seriously advocate the same intravenous fluid for a patient with watery diarrhea and serum sodium of $158 \mathrm{mmol} / \mathrm{L}$ as we would for a patient with the same amount of fluid deficit secondary to furosemide and with a serum chloride of $87 \mathrm{mmol} / \mathrm{L}$ and an arterial base excess of $10 \mathrm{mEq} / \mathrm{L}$ ? Understanding human physiology and the pathobiology of disease is no less important that knowing the results of large randomized trials.

In the articles that follow, leading experts from around world synthesize data and review pathophysiology. They provide the latest insights drawn from trials, basic science, and personal experience. They do not shy away from controversy but defend their positions with evidence. They provide a glimpse into the future and review of the past. I hope you will find this collection of articles as interesting and thought-provoking as I have.

\author{
John A. Kellum, MD, FACP \\ Center for Critical Care Nephrology \\ University of Pittsburgh \\ 604 Scaife Hall \\ Pittsburgh, PA 15213, USA
}

E-mail address: kellumja@upmc.edu

\title{
REFERENCES
}

1. Kellum JA. Preface. Crit Care Clin 2005;21(2):xiii-xv.

2. Bove T, Zangrillo A, Guarracino F, et al. Effect of fenoldopam on use of renal replacement therapy among patients with acute kidney injury after cardiac surgery: a randomized clinical trial. JAMA 2014;312(21):2244-53.

3. VA/NIH Acute Renal Failure Trial Network, Palevsky PM, Zhang JH, et al. Intensity of renal support in critically ill patients with acute kidney injury. N Engl J Med 2008;359(1):7-20.

4. RENAL Replacement Therapy Study Investigators, Bellomo R, Cass A, et al. Intensity of continuous renal-replacement therapy in critically ill patients. N Engl J Med 2009;361(17):1627-38.

5. Perner A, Haase N, Guttormsen AB, et al. Hydroxyethyl starch 130/0.42 versus Ringer's acetate in severe sepsis. N Engl J Med 2012;367(2):124-34.

6. Myburgh JA, Finfer S, Bellomo R, et al. Hydroxyethyl starch or saline for fluid resuscitation in intensive care. N Engl J Med 2012;367(20):1901-11.

7. Kidney Disease: Improving Global Outcomes (KDIGO) Acute Kidney Injury Work Group. KDIGO Clinical Practice Guideline for Acute Kidney Injury. Kidney Int Suppl 2012;2:1-138.

8. Zarbock A, Schmidt C, Van Aken H, et al. Effect of remote ischemic preconditioning on kidney injury among high-risk patients undergoing cardiac surgery: a randomized clinical trial. JAMA 2015;313(21):2133-41.

9. Goldstein SL, Kirkendall E, Nguyen H, et al. Electronic health record identification of nephrotoxin exposure and associated acute kidney injury. Pediatrics 2013; 132(3):e756-67.

10. Kellum JA. Impaired renal blood flow and the "spicy food" hypothesis of acute kidney injury. Crit Care Med 2011;39(4):901-3. 
11. Angus DC, Barnato AE, Bell D, et al. A systematic review and meta-analysis of early goal-directed therapy for septic shock: the ARISE, ProCESS and ProMISe Investigators. Intensive Care Med 2015. [Epub ahead of print].

12. NICE-SUGAR Study Investigators, Finfer S, Chittock DR, et al. Intensive versus conventional glucose control in critically ill patients. N Engl J Med 2009; 360(13):1283-97. 